\title{
KEMAMPUAN DAN KEBUTUHAN PELAKSANAAN PROMOSI KESEHATAN SEKOLAH DI SEKOLAH DASAR KOTA YOGYAKARTA
}

Capabilities And Needs For Implementing School Health Promotions In Basic Schools Yogyakarta City

\author{
${ }^{1} Y u s e r a n,{ }^{2}$ Ira Paramastri, ${ }^{3}$ M. Agus Priyanto \\ 1STIKES Cahaya Bangsa, A. Yani km 17, Kabupaten Banjar \\ 2Universitas Gadjah Mada, Bulak Sumur, Yogyakarta \\ ${ }^{3}$ Dinkes Prov. DIY, Yogyakarta \\ Email :yuseran8@gmail.com
}

\begin{abstract}
Health School Unit (Usaha Kesehatan Sekolah) or UKS is a method to maintain and improve of students health status and school environment. UKS activities were widely judged to be more active when healthy school competition and when the accreditation assessment. It is not appropriate with the philosophy UKS. Problems actual implementation of the basic values of UKS in school activities into question. Any schools in Yogyakarta have achievements in the field of UKS but others had not initiate its. Motivation in the implementation of UKS in these schools were interested to explore. This research aim to explore about motivation, capability assessment and needs assessment of Health School Affairs's implementatiot. Moreover, the research were expected to develop of School Health Affairs at Elementary School in Yogyakarta. This study used a qualitative method with case study design. Subjects in this research were stakeholder of the school that elected by purposively. While the data collection were collected through indepth interviews and focus group discussions (FGD). UKS Teachers have not been able to manage UKS, especially UKS administration. UKS teachers could not to manage UKS especially the administration of UKS. Futhermore, the activity at the achievement school only limited for caring student who sick but the school did not achievement just write of referral and attend the invitation. Human resources at the school have not understood about the functions of UKS and have not been able to carry out the task of UKS because of the limitation of their time. The schools need a good coaching, management of comprehensive planning program, training, education, guidelines and policies that more detailed, and collaboration.
\end{abstract}

Keywords : Ability, Needs, School Health Unit (UKS), Elementary School

\begin{abstract}
Abstrak
Usaha kesehatan sekolah (UKS) merupakan upaya pemeliharaan dan peningkatan kesehatan anak dan lingkungan sekolah. Beberapa sekolah di Kota Yogyakarta telah mendapatkan prestasi dalam UKS. Kegiatan UKS saat ini banyak dinilai menjadi lebih aktif ketika lomba sekolah sehat dan ketika penilaian akreditasi. Hal tersebut terlihat jauh dari filosofi UKS sendiri. Beberapa sekolah memiliki prestasi di bidang UKS dan beberapa sekolah lain bahkan belum mengembangkannya. Kemampuan dan penilaian kebutuhan dalam implementasi UKS di sekolah-sekolah tersebut menjadi menarik untuk dikaji sebagai bahan pendalaman kajian nilai-nilai UKS di sekolah. Penelitian ini merupakan penelitian kualitatif studi kasus. Subjek penelitian adalah stakeholder UKS secara purposif yang dikumpulkan melalui wawancara mendalam dan diskusi kelompok terarah (DKT). Guru UKS belum mampu mengelola UKS, terutama administrasi UKS. Kegiatan guru UKS pada sekolah berprestasi sebatas pelayanan pada murid yang sakit dan pada sekolah tidak berprestasi kegiatan sebatas menulis rujukan dan menghadiri undangan. SDM UKS belum mampu dalam memahami tugas dan fungsi UKS serta belum sanggup dalam melaksanakan tugas UKS karena tugas rangkap dan keterbatasan waktu. Sekolah membutuhkan pembinaan UKS yang baik, manajemen perencanaan program yang komprehensif, pelatihan dan pendidikan lanjutan, pedoman dan kebijakan dalam penyelenggraan UKS yang lebih rinci, dan kolaborasi.
\end{abstract}

Kata Kunci : Kemampuan, Kebutuhan, Usaha Kesehatan Sekolah, Sekolah Dasar 


\section{PENDAHULUAN}

Sekolah menempati kedudukan strategis dalam upaya promosi kesehatan karena sebagian besar anak-anak usia 5-19 tahun terpajan dengan lembaga pendidikan dalam jangka waktu yang cukup lama (Kemdiknas, 2011). Berdasarkan data Pendidikan Nasional tahun 2009/2010 persentase anak usia 7-12 tahun yang sekolah dijenjang SD/MI mencapai 98,3\%. Beberapa permasalahan atau resiko terhadap anak banyak ditemukan dalam beberapa penelitian seperti warung sekolah yang belum memenuhi syarat, sanitasi lingkungan yang tidak memadai dan masalah kebersihan siswa (Arifin, 2005; Sidharahardja, 2008). UKS merupakan sebagai sarana penting dalam meningkatkan derajat kesehatan warga sekolah, orangtua dan masyarakat lingkungan sekolah melalui upaya promotif, preventif tanpa mengesampingkan kuratif dan rehabilitatif (Lee, et all., 2008; Depkes RI, 2008). Namun beberapa kendala banyak ditemukan dalam penyelenggaraan dan pengembangan UKS diantaranya pembinaan dari tim pembina yang belum maksimal, kegiatan sebatas pelayanan kesehatan dan lain sebagainya (Kemenkes RI, 2011; Yudho, 2011; Sidharahardja, 2008).

Salah satu UKS sekolah dasar di kota Yogyakarta telah berhasil memenangkan lomba sekolah sehat sampai pada jenjang tingkat provinsi dan akan menuju tingkat nasional. Hal tersebut mengindikasikan bahwa sekolah tersebut memiliki kemampuan dan motif yang baik dalam penyelenggaraanya mengingat masih banyak sekolah yang memiliki kendala dalam penyelenggaraan UKS. Disamping itu berdasarkan studi pendahuluan ditemukan bahwa pelaksanaan UKS lebih difokuskan pada kegiatan perlombaan sekolah sehat dan untuk syarat akreditasi. Hal ini tentu sangat berbeda dengan tujuan utama promosi kesehatan sekolah atau UKS.

Fenomena tersebut menarik perhatian bagi peneliti, maka untuk mengungkap fenomena tersebut digunakan salah satu teori bahwa produktifitas dipengaruhi oleh motivasi dan kemampuan (Gomes, 2003; Muhammadi et. all., 2010; Tjomsland et. all., 2009). Selanjutnya perlu juga diketahui kebutuhan yang diperlukan dalam penyelenggaraan dan pengembangan UKS sehingga dapat membantu dalam pengembangan program promosi kesehatan yang komprehensif, unik, cocok dengan kebutuhan dan kemampuan sekolah (McBride et. all., 1999).

\section{BAHAN DAN METODE}

Penelitian ini merupakan jenis penelitian kualitatif dengan strategi studi kasus (Cresswell, 2010). Tipe diskriptif desain kasus tunggal terjalin (unit multi analisis), jenis struktur laporan analitislinear (Yin, 2004). Subjek penelitian dilakukan secara purposive. Informan sekolah dasar berprestasi (Muhammadiyah Suronatan) : 1 kepala sekolah, 1 guru UKS, 1 guru olahraga, 1 guru bahasa inggris, 1 guru agama, 6 murid dan 1 wali murid. Adapun informan sekolah dasar tidak berprestasi yaitu 1 kepala sekolah, 1 guru kelas, 3 orang murid dan 2 orang wali murid. Informan pendukung terdiri 2 dari tim pembina kecamatan/Puskesmas, 1 orang tim pembina kota/dinas kesehatan kota dan 1 tim pembina provinsi/dinas pendidikan provinsi. Pengumpulan data primer (wawancara mendalam, observasi, dokumentasi). Instrumen penelitian : pedoman wawancara dan pedoman observasi. Trustworthiness data dilakukan dengan Credibilty (Triangulation, Peer debriefing, Member checking), Transferability, dan Dependabilty (Yin, 2004). Analisis data dilakukan bersamaan dengan pengumpulan data (on going analysis). Proses analisis data meliputi: reduksi data, menyajikan data, dan menarik kesimpulan (Gugglberger dan Dur, 2011).

\section{HASIL DAN PEMBAHASAN}

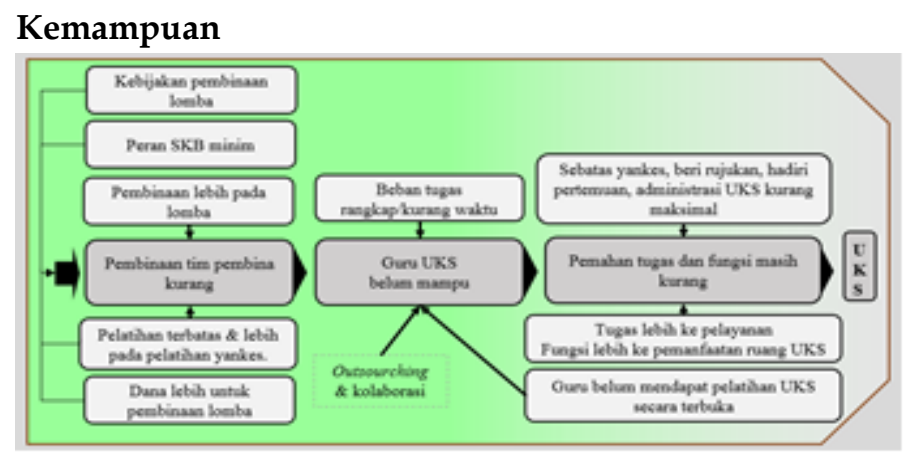

Tabel 1. Bagan kemampuan ekstrinsik stakeholder tim pelaksana sekolah dalam penyelenggaraan UKS. 
Kemampuan memahami tugas dan fungsi sangat penting dalam mencapai tujuan dari pelaksanaan program UKS. Beberapa stakeholder sekolah masih belum mampu memahami tugas dan fungsi pelaksana UKS secara utuh. Pelaksana UKS sebaiknya tahu pada tugas dan fungsi dari pelaksana UKS agar pelaksanaan UKS dapat lebih terarah dan dapat meningkatkan hasil dari pelaksanaan UKS itu sendiri. Hasil ini mengkonfirmasi penelitian sebelumnya yang menunjukkan kurangnya pemahaman dalam memahami HPS (Muhammadi et, all., 2010). Pentingnya stakeholder dalam memahami HPS dalam penyelenggaraan UKS telah dijelaskan dalam beberapa penelitian (Muhammadi et. all., 2010; McBride et. all., 1999; Reutersward dan Lagerstrom, 2009). Kemampuan seseorang dalam memahami dipengaruhi oleh pengetahuan yang dapat diperoleh dari sumber informasi yang dijadikan sebagai pedoman (Thoha, 2012).

Kemampuan seseorang juga bisa dilihat dari kesanggupan seseorang dalam melaksanakan tugasnya. Informan merasa belum mampu dalam melaksanakan tugasnya terutama dalam hal administrasi UKS dan terlihat berdasarkan temuan sebelumnya pada tim pelaksana belum mampu menggunakan manajemen perencanaan program yang maksimal. Hal tersebut disebabkan karena beban tugas sebagai guru kelas sudah cukup menyibukkan dan terkait kekurangan waktu dalam mengurus UKS. Berikut sebagaimana disampaikan informan:

kalo tim pelaksana UKS yang di sekolah ini sementara ini ya memang maaf sambil disambi gitu lo mas (guru UKS sekolah berprestasi) sekolah sekolah itukan asal sudah kerja ngajar tugasnya selesai toh tapi yang mau mengembangkan untuk mengembangkan seperti itu harus ada orang yang punya potensi sendiri yang harus punya duduk didalam UKSnya itu sendiri makanya outsourcing larinya kan gitu (Tim Pembina UKS Kota/Dinkes)

Variabel beban kerja memiliki efek negatif yang signifikan terhadap kualitas dan kuantitas kerja. Lebih lanjut hal tersebut menunjukkan jika karyawan memiliki kelebihan kerja, maka kuantitas dan kualitas kinerja karyawan akan berkurang (Yassierli, 2013). Hasil ini mengkonfirmasi penelitian sebelumnya yang menunjukkan bahwa staf sekolah yang dipekerjakan di sekolah tidak bisa maksimal karena kekurangan waktu akibat beban tugas pokok dasar (Reutersward dan Lagerstrom, 2009; Keshavarz et. all., 2010). Komitmen waktu dan tenaga merupakan elemen penting dalam keberhasilan program promosi kesehatan sekolah (McBride et. all., 1999). Memberikan pembagian waktu jam kerja guru disarankan dalam penelitian ini (Gugglberger dan Dur, 2011).

Kurangnya waktu yang dimiliki staf dapat menghilangkan antusiasme dalam menjalankan HPS karena rasa kepemilikan oleh masing-masing sekolah tidak cukup (Hung et. all., 2014). Hal ini terlihat juga pada sekolah bahwa guru memiliki beban kerja akibat dari kekurangan waktu untuk mengurus UKS dampaknya tugas guru sebatas pelayanan kesehatan seperti melayani jika ada anak sakit dan menata ruang UKS. Berdasarkan analisis peneliti bahwa keterbatasan guru dalam UKS tidak dapat disalahkan karena pada buku pedoman pelaksanaan UKS di sekolah juga tidak secara khusus memberikan tugas atau peran terhadap masing-masing staf sekolah. Buku pedoman hanya memberikan tugas secara umum yaitu tugasnya hanya ditujukan pada tim pelaksana dan tidak secara khusus memberikan tugas kepada guru dan lainnya.

Dalam rangka mengembangkan rasa kepemilikan ini, maka pedoman HPS harus memungkinkan anggota dapat memainkan peran yang jauh lebih lengkap dalam perencanaan strategis dan pengambilan keputusan profesional, serta penggerak kesehatan juga harus diberdayakan dengan otonomi untuk mengatur promosi kesehatan sebagai prioritas, dengan kerangka/pedoman yang fleksibel dalam penafsirannya dari analisis kebutuhan sekolah, mengembangkan tujuan dan dan sasaran promosi kesehatan sekolah, alokasi anggaran, pelaksanaan dan evaluasi hasil (Hung et. all., 2014). Menurut analisis peneliti sekolah membutuhkan pedoman yang lebih jelas sehingga dapat mengembangkan rasa kepemilikan dalam melaksanakan UKS. Kebutuhan tersebut merupakan jenis kebutuhan normatif (Ewles dan Simnett, 1994). 
SDM yang selalu ada atau tenaga out sourcing yang dapat fokus dan penuh mengelola UKS dinilai dibutuhkan guru UKS dan pembina dalam mengatasi kuarangnya waktu guru. Hal senada dalam penelitian bahwa para perawat kesehatan di sekolah memberikan ide dengan memanfaatkan kualifikasi dokter sekolah spesialis penyakit anakanak dan ahli kesehatan lainnya yang dapat menjadikan lebih baik dalam pelayanan kesehatan (Reutersward dan Lagerstrom, 2009). Ahli promosi kesehatan dipandang sangat signifikan dalam kemajuan program (Inchley et. all., 2006).

Berdasarkan temuan penelitian pada hasil motivasi, sekolah berprestasi sudah berkolaborasi dengan berbagai instansi, namun kolaborasi tersebut lebih pada pelayanan kesehatan. Menurut analisis peneliti sekolah membutuhkan kolaborasi pada tingkat pelaksanaan UKS secara keseluruhan. Kebutuhan tersebut merupakan jenis kebutuhan normatif (Ewles dan Simnett, 1994). Kami menyarankan kolaborasi dengan tenaga ahli Ahli promosi kesehatan dapat dijadikan sebagai koordinator kunci dan dipandang sangat signifikan dalam kemajuan program, serta dapat memainkan peran penting dalam menjaga terkait dengan HPS dan untuk membuat hubungan antara pihak terkait (McBride et. all., 2003; Inchley et. all., 2006; Leurs et.all., 2005). Pentingnya kolaborasi yang tepat disarankan dalam beberapa penelitian hal ini dapat mendorong pertukaran pengalaman dan gagasan dalam pelaksanaan HPS (McBride et. all., 1999; Hung et. all., 2014; Macnab et. all., 2014). Kolaborasi juga bisa dilakukan dengan kerjasama dengan perguruan tinggi terkait. Perguruan tinggi dapat menempatkan mahasiswanya di UKS sekolah sebagai praktik kerja nyata atau praktik kerja lapangan, sehingga ini dapat memberikan keuntungan bagi kedua belah pihak (Gugglberger dan Dur, 2011; Plessis et. all., 2014). Selain itu kolaborasi dengan profesional eksternal, partisipasi murid dan keterlibatan orangtua juga penting (Inchley et. all., 2006).

Pendekatan kolaboratif dapat membawa efek keberlanjutan dalam promosi kesehatan sekolah (Hung et. all., 2014). Namun kolaboratif perlu pembagian tanggung jawab yang jelas agar mereka dapat fokus dengan bidang profesional mereka, hal ini juga harus ditunjang dengan membangun pemahaman bersama mengenai prinsip-prinsip dan nilai-nilai serta negosiasi tujuan dan harapan yang disepakati bersama sangat penting dalam tim multidisiplin.

Kemampuan tim pelaksana sekolah juga dipengaruhi pembinaan dari tim pembina yang masih kurang. Pembinaan lebih maksimal ketika pembinaan pada saat lomba. Begitu juga dengan pelatihan masih terbatas. Adapun pelatihan dari kecamatan yaitu puskesmas tidak secara khusus melatih UKS secara keseluruhan, lebih pada pelatihan terkait dengan lancarnya program UKS puskesmas, misalnya pelatihan cara pengukuran tinggi badan dan berat badan. Pelatihan dari dinas pendidikan masih terbatas dengan pendanaan dan program yang ada lebih pada pembinaan untuk lomba. Perawat kesehatan sekolah masih kurang memiliki pengetahuan tentang teori dan metode dalam pekerjaan promosi kesehatan di sekolah, kurang pemahaman tersebut menyiratkan keterbatasan dalam pelaksanaannya. Pekerjaan perawat lebih kepada tingkat individu murid dan tidak melakukan pada tingkat kelompok. Hal tersebut disebabkan pula oleh pelatihan yang mereka terima tidak relevan dengan pekerjaan (Reutersward dan Lagerstrom, 2009).

Dampak dari kurangnya pelatihan dan kurang menyeluruhnya pelatihan terhadap UKS diakui oleh guru UKS yang mengatakan bahwa pengetahuan mengenai UKS secara ideal belum dimiliki karena pelatihan belum terbuka dan memang tidak ada penyampaian khusus tentang UKS. Untuk memenuhi kekurangan tentang pengetahuan UKS hanya diskusi dengan guru sekolah lain. Para perawat sekolah merasakan bahwa pengetahuan yang mereka peroleh dari pelatihan tidak relevan dengan pekerjaan promosi kesehatan sekolah. Lebih lanjut dikatakan bahwa perawat melakukan hal-hal dengan cara yang sama seperti rekan-rekan yang berpengalaman atau mereka bekerja sesuai dengan pengalaman terbaik mereka sendiri (Reutersward dan Lagerstrom, 2009). Penyelenggaraan UKS membutuhkan pelatihan dan pendidikan dalam promosi kesehatan. Kebutuhan tersebut adalah jenis kebutuhan yang dinyatakan Ewles and Simnett (1994). Kebutuhan akan pentingnya dilakukan pelatihan dan pendidikan lanjutan disarankan dalam 
beberapa penelitian (Gugglberger dan Dur, 2011; Keshavarz et. all., 2010.

\section{KESIMPULAN}

Kemampuan tim pelaksana dipengaruhi oleh masih kurangnya pelatihan yang ideal terkait UKS, yang ada sekarang lebih pada pelatihan pelayanan kesehatan bukan pelatihan UKS yang menyeluruh. Kemampuan tim pelaksana juga dipengaruhi oleh pembinaan dari tim pembina yang belum maksimal karena pembinaan yang ada sekarang lebih fokus pembinaan bagi sekolah yang memenangkan lomba sekolah sehat. Pembinaan dari tim pembina yang tidak maksimal karena kebijakan terkait pendaaan hanya cukup untuk kegiatan lomba termasuk pembinaan untuk pemenang lomba. Kurang maksimalnya pembinaan juga dipengaruhi oleh peran SKB yang masih minim sehingga pembinaan UKS tidak terkoordinir baik. Sekolah perlu aktif untuk mencari dan ikut dalam pelatihan dan pendidikan lanjutan, aktif dalam membangun hubungan dan membina interaksi baik antar sekolah, sektor kesehatan, perlunya berkolaborasi dan menerima kolaborasi yang relevan, sekolah diharapkan memainkan peran yang banyak agar rasa kepemilikan terhadap UKS tumbuh, namun perlu diperhatikan dukungan keuangan dan waktu untuk kontribusi tambahan guru UKS.

\section{DAFTAR PUSTAKA}

Arifin, A., 2005. Pengembangan Model Sekolah Sehat (Health Promoting School) di Daerah Miskin Perkotaan. Buletin Penelitian Sistem Kesehatan, Vol. 8 No. 1 Juni 2005, hal. 20-28.

Cresswell, J. W., 2010. Pendekatan Kualitatif, Kuantitatif, dan Mixed. Alih bahasa Achmad Fawaid. Yogyakarta: Pustaka Pelajar.

Depkes RI, 2008. Promosi Kesehatan di Sekolah. Jakarta. Ewles, L. and Simnett, I., 1994. Promoting Health A Practical Guide, Second Edition (Edisi Terjemahan), Emilia, O., 1994 (alih bahasa). Promosi Kesehatan. Edisi Kedua. Gadjah Mada University Press : Yogyakarta.

Gomes, Faustino Cardoso., 2003. Manajemen Sumber Daya Manusia. Yogyakarta: Andi Offset.
Gugglberger, L., and Dur, W., 2011. Capadalamy building in and for health romoting schools: Results from a qualitative study', Health Policy. ELSEVER.

Hung, T.T.M., Chiang, V.C.L., Dawson, A., and Lee, R.L., 2014. Understanding of Factors that Enable Health Promoters in Implementing Health-Promoting Schools: A Systematic Review and Narrative Synthesis of Qualitative Evidence'. Plos One.

Inchley J, Muldoon J, Currie C., 2006. Becoming a health promoting school: evaluating the process of effective implementation in Scotland.http://www.ncbi.nlm.nih.gov/pu bmed/.

Kementerian Pendidikan Nasional RI, 2011. Pedoman Pelaksanaan UKS di Sekolah. Jakarta.

Kementerian Kesehatan RI, 2011. Menteri Kesehatan terima Pemenang Lomba Sekolah Sehat Tingkat Nasional 2011. http://www.depkes.go.id /index.php/berita/press release/1639menkes - terima - pemenang-lombasekolah-sehat-tingkat nasional-2011.html. [diakses tanggal 3 Juni 2012].

Keshavarz, N. Nutbeam, D., Rowling, L., and Khavarpour, F., 2010. Schools as social complex adaptive systems: A new way to understand the challenges of introducing the health promoting schools concept. Social Science \& Medicine. ELSEVIER.

Lee, A. Wong, M.C. Keung, V. M. Yuen, H. S. Cheng, F. Mok, J. S., 2008. Can the concept of Health Promoting Schools help to improve students' health knowledge and practices to combat the challenge of communicable diseases: Case study in Hong Kong?'. Biomedcentral (BMC Public Health), 8-42.

Leurs, M.T.W. Schaalma, H.P. Jansen M.W.J. Veeman, I.M.M. Leger, L.H.ST. Vries, N.D., 2005. Development Of A Collaborative Model To Improve School Health Promotion In The Netherlands', $\backslash$ Health Promotion International. Oxford University Press. Vol 20. No 3 .

Macnab, A. J. Stewart, D. Gagnon, F. A., 2014. Health promoting schools: initiatives in Africa'. Emerald, Helath Education, Vol. 114 No. 4. 
McBride, N. Midford, R. dan Cameron, I., 1999. An Empirical model for school health promotion: the western Australian school health project model' Health Promotion International. Oxford University Press. Vol 14. No 1.

Muhammadi, N.K. Rowling, L. and Notbeam D., 2010. Acknowledging Educational Perspectives on Health Promoting School, Qazvin University for Medical Sciences, Qazvin, Iran. Faculty of Education and Social Work, University of Sydney, Sydney. University of Southampton, Southampton, UK, Emerald Journal. Vol. 110, No. 4, February 2010, 240-251.

Plessis, L.M.d. Koornhof, H.E. M. Daniels, L.C. Sowden, M. Adams, R., 2014. Healthpromoting schools as a service learning platform for teaching health-promotion skills'. African Journal of Health Professions Education (AJHPE), Vol. 6, No. 1.

Reutersward, M. dan Lagerstrom, M., 2009. The aspects school health nurses find important for successful health promotion. Scandinavian Journal of Caring Sciences.

Sidharahardja, I., B., K., 2008. Pengaruh Pelatihan Model Sekolah Sehat Pada Guru Sd Terhadap
Peningkatan Pengetahuan Dan Perilaku Kesehatan Siswa Sd di Kabupaten Bulungan Kalimantan Timur, Tesis. Universitas Gadjah Mada.

Thoha, M., 2012. Perilaku Organisasi : Konsep dasar dan aplikasinya. Jakarta : Rajawali Pers.

Tjomsland, H.E. Iversen, A.C. and Wold, B., 2009. The Norwegian Network of Health Promoting Schools: A Three-Year Follow-Up Study of Teacher Motivation, Participation and Perceived Outcome, University of Bergen, Scandinavian Journal of Educational Research. Vol. 53, No. 1, February 2009, 89102.

Yassierli, Hardjomidjojo, P dan Aisha, N.A., 2013 Effect of working Ability. Working Condition, Motivation and Incentive on Employees Multi-Dimensional Performance. International journal of Innovation, Management and Technology, Vol. 4, No. 6.

Yin, R.K., 2004. Studi Kasus, Desain dan Metode. Jakarta : PT. Raja Grafindo Persada.

Yudho, 2011. Kemitraan dan Kepemimpinan dalam Implementasi Usaha Kesehatan Sekolah (UKS) Di Kecamatan Mentawa Baru Ketapang Kabupaten Kota Waringin Timur, Tesis. Universitas Gadjah Mada. 